\title{
Sexual segregation of Echinorhynchus borealis von Linstow, 1901 (Acanthocephala) in the gut of burbot (Lota lota Linnaeus)
}

\author{
Arto Tuomainen ${ }^{1}$, E. Tellervo Valtonen ${ }^{1}$ and Daniel P. Benesh ${ }^{1,2}$ \\ ${ }^{1}$ Department of Biological and Environmental Science, University of Jyväskylä, Finland; \\ ${ }^{2}$ Marine Science Institute, University of California, Santa Barbara, CA, USA
}

\begin{abstract}
Helminths often occupy defined niches in the gut of their definitive hosts. In the dioecious acanthocephalans, adult males and females usually have similar gut distributions, but sexual site segregation has been reported in at least some species. We studied the intestinal distribution of the acanthocephalan Echinorhynchus borealis von Linstow, 1901 (syn. of E. cinctulus Porta, 1905) in its definitive host, burbot (Lota lota Linnaeus). Over $80 \%$ of female worms were found in the pyloric caeca, whereas the majority of males were in the anterior two-thirds of the intestine. This difference was relatively consistent between individual fish hosts. Worms from different parts of the gut did not differ in length, so site segregation was not obviously related to worm growth or age. We found proportionally more males in the caeca when a larger fraction of the females were found there, suggesting mating opportunities influence gut distribution. However, this result relied on a single parasite infrapopulation and is thus tentative. We discuss how mating strategies and/or sexual differences in life history might explain why males and females occupy different parts of the burbot gut.
\end{abstract}

Keywords: thorny-headed worms, body size, Echinorhynchidae, Echinorhynchus cinctulus, microhabitat, niche, sex ratio, spatial distribution

Helminths that reproduce in the gastrointestinal tract of vertebrates usually do not occur freely throughout the gut. Any given species tends to be restricted to specific portions of the gut (Crompton 1973). Nutrient availability and physiology (e.g. Mettrick and Podesta 1974, 1982, Haukisalmi et al. 1998, Richardson and Nickol 2000), intra- and interspecific competition (e.g. Holmes 1961, Bush and Holmes 1986), and mating (e.g. Rohde 1994) have all been proposed as important determinants of the distribution of helminths along the gut. Adult acanthocephalans often have well-defined microhabitat preferences in the definitive host gut (e.g. Awachie 1966, Uglem and Beck 1972, Kennedy 1985, Al-Jahdali and El-Said Hassanine 2012).

However, within a species, the distributions of male and female worms do not always perfectly overlap (Kennedy and Lord 1982, Serov 1985, Aznar et al. 2001, Robinson and Barger 2007). This may be a consequence of divergent life history strategies (e.g. sexual dimorphism is widespread in acanthocephalans; Poulin and Morand 2000, Benesh and Valtonen 2007), or it may reflect the reproductive success of each sex being maximised by occupying different parts of the gut. In any case, documenting the within-host distribution of males and females in additional acanthocephalan species will help understand when and why gut position differs between the sexes.

We studied the distribution of the acanthocephalan Echinorhynchus borealis von Linstow, 1901 in the gut of its definitive host, burbot (Lota lota Linnaeus). Wayland et al. (2015) recently proposed that the correct name for this species is E. cinctulus Porta, 1905, but we use E. borealis here, as essentially all previous work referred to the worm by this name. Burbot is considered the main definitive host for $E$. borealis, although it has been reported from a handful of other fish species (Grabda-Kazubska and Ejsymont 1969). The intermediate host is the amphipod Pallasea quadrispinosa Sars (see Valtonen and Crompton 1990, Benesh et al. 2008), a glacial relict that occurs in the cold, epibenthic portion of freshwater lakes (Hill 1988) and is thought to have originated in Lake Baikal (Segerstråle 1962). Adult burbot also tend to prefer cold waters below the thermocline (McPhail and Paragamian 2000), so the entire life cycle of E. borealis takes place in the benthos (Fig. 1).

\section{MATERIALS AND METHODS}

Burbot were caught from Lake Leppävesi, central Finland $\left(62^{\circ} 18^{\prime} \mathrm{N} ; 25^{\circ} 56^{\prime} \mathrm{E}\right)$ with gill nets $(60$ long $\times 5 \mathrm{~m}$ high, mesh size of $55 \mathrm{~mm}$ ). Leppävesi is a slightly eutrophic lake, 3100 ha in

Address for correspondence: D.P. Benesh, Marine Science Institute, University of California, Santa Barbara, CA 93106-6150, USA.

E-mail: daniel.benesh@lifesci.ucsb.edu 


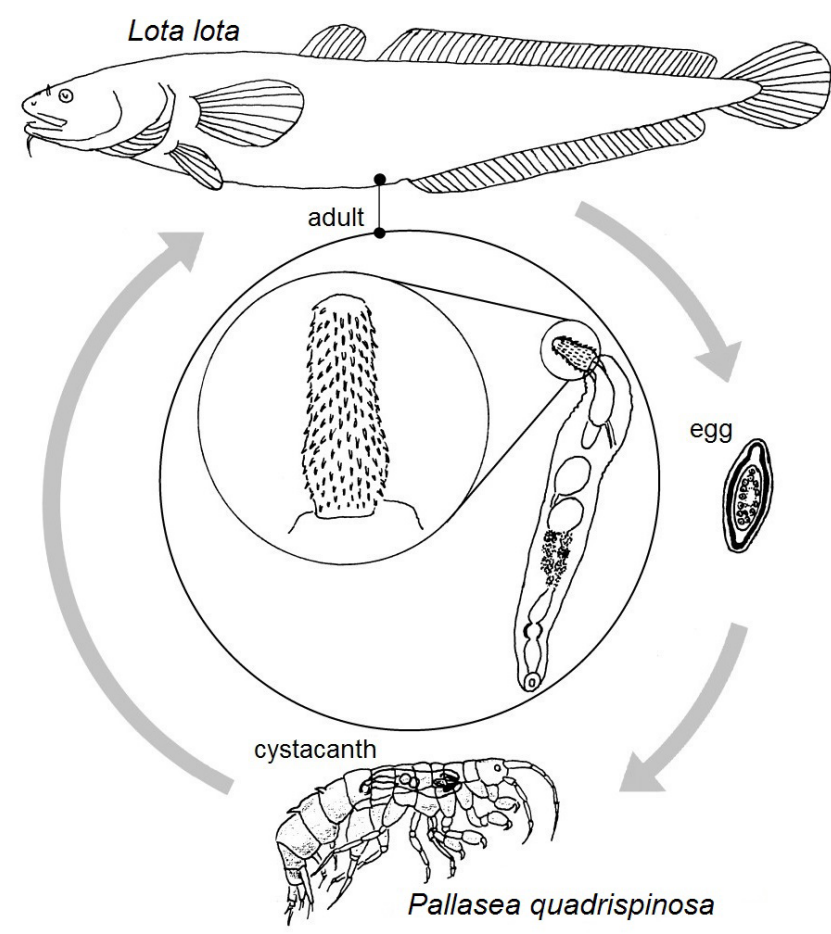

Fig. 1. The life cycle of Echinorhynchus borealis von Linstow, 1901. Burbot (Lota lota Linnaeus) are the usual definitive host with the glacial relict amphipod Pallasea quadrispinosa Sars serving as intermediate host.

area, with a max depth of $41 \mathrm{~m}$. It drains via Lake Päijänne and the Kymijoki River to the Gulf of Finland in the Baltic Sea. Fish were caught between June 2005 and May 2006, with the majority (22/27) being collected between October 2005 and January 2006. They were either dissected within a day of capture or frozen at $-20^{\circ} \mathrm{C}$ for later examination. The entire gastrointestinal tract was examined for Echinorhynchus borealis. It was divided into four distinct microhabitats: the pyloric caeca, the anterior third of the intestine, the middle third, and the posterior third. The caeca are 'blind sacks' attached to the proximal intestine. They are numerous in burbot (tens of them) and make up a substantial proportion of the total weight of digestive tissue in the whole gut (Izvekova et al. 2013). The location, sex and length of worms were recorded. Recovered acanthocephalans were placed into refrigerated tap water overnight to relax and extend prior to measurements.

Our dataset contained some gaps. Two worms from two fish were damaged during dissection and were not measured. Also, in the first three fish dissected, worms were only recorded as being in the caeca or the intestine and were not measured ( $\mathrm{n}=295$ worms). In the most heavily infected fish (intensity $=172$ ), only a random subset of the worms $(n=89)$ were sexed and measured. We tried different methods of addressing the missing data (listwise deletion, pairwise deletion and multiple imputation) and found that the results were qualitatively similar. The reported results are based on pairwise deletion, where particular fish were excluded from some, but not all, analyses. We considered this approach a suitable balance between maximising data use and simplicity.

The distribution of male and female worms in the intestine of burbot was compared with a chi-square test. This test is at the level of the component population (i.e. parasites from all fish; see Bush et al. 1997), and it might hide significant differences among fish hosts (see e.g. Kennedy 1985). We therefore also performed a Cochran Mantel Haenszel test (Agresti 2013), in which the data are stratified into separate contingency tables for each fish. Chi-square tests can be biased when counts are not independent (Kramer and Schmidhammer 1992). In our case, this might apply if the habitat choice of an individual worm is affected by other worms in the same gut (e.g. Bush and Holmes 1986, Moore and Simberloff 1990). We tested whether worm distribution was intensity-dependent by fitting logistic regressions in which the proportion of male or female worms in the caeca was the response variable and infection intensity was the predictor variable. Similarly, to examine whether male and female habitat use co-varies, we fit a logistic regression for the proportion of males in the caeca, using the proportion of females in the caeca as a predictor. Finally, we used linear mixed models to compare worm length among gastrointestinal habitats (fish individual as random effect; habitat, worm sex and intensity as fixed effects).

\section{RESULTS}

We collected and dissected 27 burbot (mean length \pm SD $=493 \pm 53 \mathrm{~mm}$ and mean weight $905 \pm 311 \mathrm{~g}$ ), of which 26 were infected with Echinorhynchus borealis (96\%). The sample abundance was $33.3(\mathrm{SD}=43.4)$, and the maximum intensity 172 . The overall sex ratio in the component E. borealis population (females : males) was $1.76: 1$.

There were clear differences in the distribution of male and female $E$. borealis in burbot $\left(\chi_{3}^{2}=81.15, \mathrm{P}<0.0001\right)$. Females were more common in the pyloric caeca and males were over-represented throughout the intestine, particularly in the anterior intestine (Fig. 2A). A Cochran Mantel Haenszel test, which accounts for the component population being broken into separate infrapopulations in each fish, was also significant $\left(\chi_{3}^{2}=65.96, \mathrm{P}<0.0001\right)$.

However, this test assumes that patterns are consistent across strata (fish in our case). We simplified our microhabitat classification to just caeca $v s$ intestine, so that a series of $2 \times 2$ tables (habitat by worm sex) could be analysed for homogeneity across fish with a Breslow-Day test. For this test, we also restricted the data to fish with at least 5 worms $(n=18)$, as lower intensity infections give little information on parasite distribution within a host. The test was non-significant $\left(\chi_{17}^{2}=21.07, \mathrm{P}=0.22\right)$, indicating that the microhabitat preferences of males and females were relatively consistent across fish (Fig. 2B).

Figure 2B still depicts some variation between fish, but this variation is not clearly explained by infection intensity. Neither the proportion of males in the caeca (logistic regression, LRT, $\chi_{1}^{2}=0.07, \mathrm{P}=0.79$ ) nor the proportion of females in the caeca $\left(\chi_{1}^{2}=0.34, \mathrm{P}=0.56\right)$ changed with the total number of worms in a fish. However, more males are found in a fish's caeca when a larger fraction of the infrapopulation's females are there $\left(\chi_{1}^{2}=12.27, \mathrm{P}<0.001\right)$ (Fig. 3). This result strongly depended on one fish with relatively few females in the caeca. When this fish was removed, the regression was no longer significant $\left(\chi_{1}^{2}=1.31\right.$, $\mathrm{P}=0.25)$.

Adult female E. borealis (total length $8.89 \pm 1.25 \mathrm{~mm}$, $\mathrm{n}=336)$ were larger than males $(5.95 \pm 0.75 \mathrm{~mm}, \mathrm{n}=182)$. The vast majority of females $(96 \%)$ had at least some eggs 

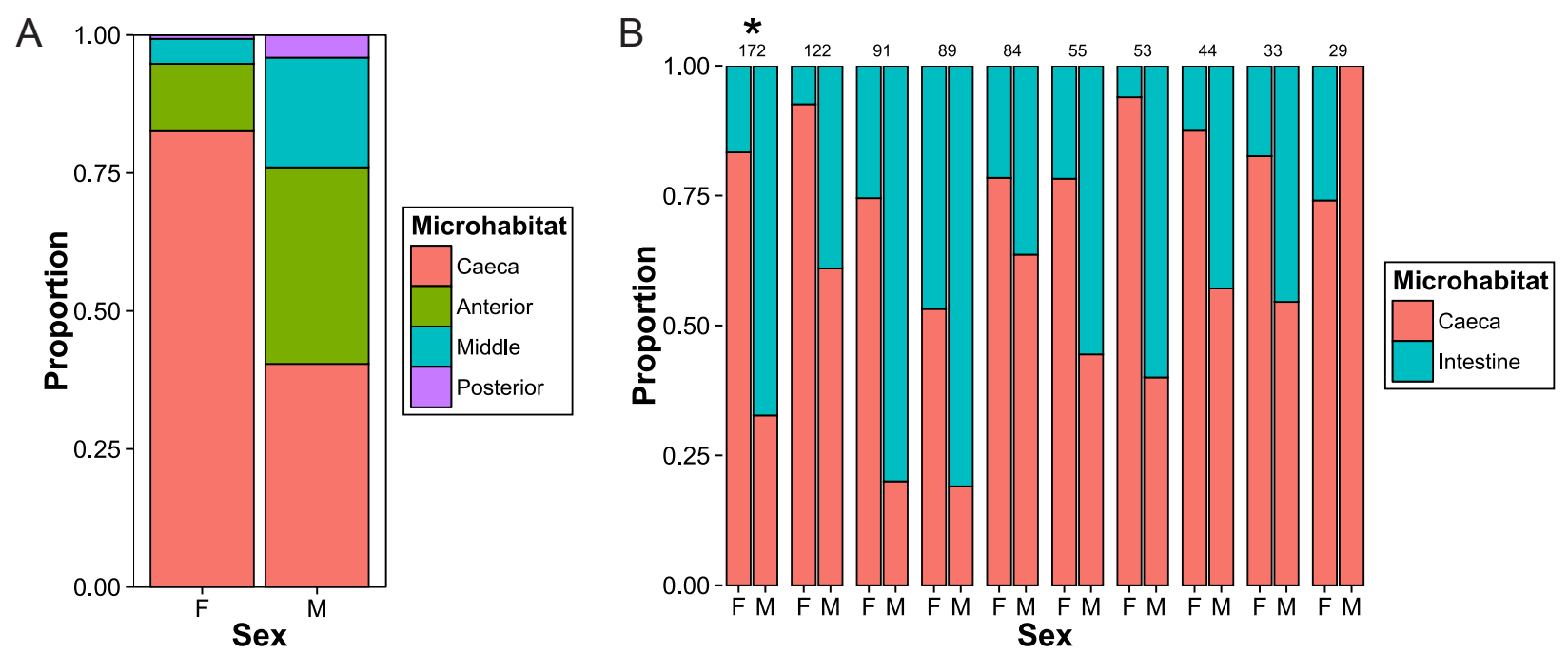

Fig. 2. The distribution of female and male Echinorhynchus borealis von Linstow, 1901 in the gastrointestinal tract of burbot (Lota lota Linnaeus) (A) at the level of the component population and (B) in separate infrapopulations. In (A), 'anterior', 'middle' and 'posterior' refer to thirds of the intestine. In (B), parasite distribution is shown for the ten most heavily infected fish with the numbers above the bars representing the infection intensities. In the most heavily infected fish (asterisk), we did not sex all the worms from the caeca; the values shown on the figure assume that the subsampled worms were representative of all worms in the caeca.

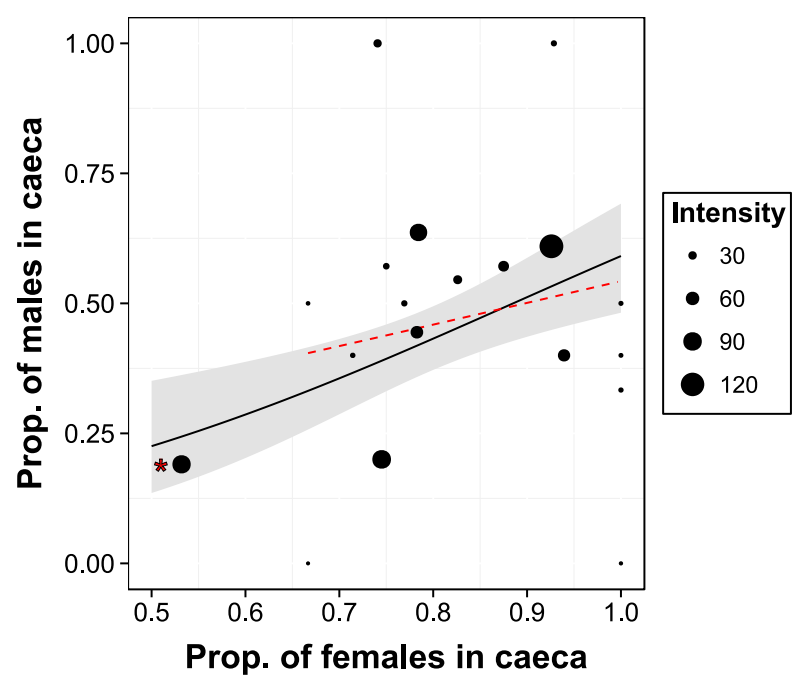

Fig. 3. The proportion of males and females of Echinorhynchus borealis von Linstow, 1901 in each fish found in the caeca. Point size is proportional to the intensity of infection. The solid line depicts the relationship predicted by logistic regression $( \pm 95 \%$ $\mathrm{CI})$. When the starred data point on the lower left is removed, the regression was shallower (red, dashed line) and not significant.

in their body cavities. Worm length did not vary between microhabitats in general (mixed model, LRT for habitat main effect; $\chi_{3}^{2}=1.04, \mathrm{P}=0.79$ ) or in a sex-specific manner (LRT for sex by habitat interaction; $\chi_{3}^{2}=6.29$, $\mathrm{P}=0.10$ ) (Fig. 4). Intensity did not have a general (LRT for intensity main effect; $\chi_{1}^{2}=0.74, \mathrm{P}=0.39$ ) or sex-specific effect on worm length (LRT for sex by intensity interaction; $\chi_{1}^{2}=0.75, P=0.39$ ). Fish identity, the random effect, explained $41 \%$ of the residual variation in worm length, indicating that certain fish harboured consistently smaller or larger worms. This may be attributable to biological differences between individual fish and/or simply methodological variation (e.g. whether a fish was frozen or not before

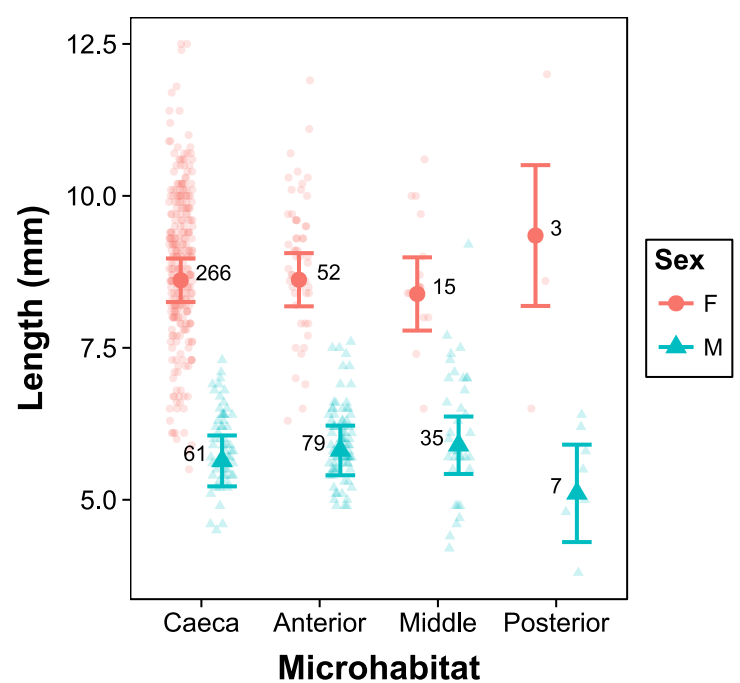

Fig. 4. The length of female and male Echinorhynchus borealis von Linstow, 1901 in different parts of the gastrointestinal tract of burbot (Lota lota Linnaeus). Means with error bars (95\% CI) were estimated with a mixed model and are overlaid on data points representing the length of individual worms. The data points have been randomly jittered horizontally to illustrate the data distribution. Numbers are sample sizes.

dissection; worms from the same fish were also measured at the same time).

\section{DISCUSSION}

We observed marked sexual site segregation in Echinorhynchus borealis. Most females (>80\%) were found in the pyloric caeca, whereas the majority of males were found in the first two-thirds of the intestine. Although the share of worms in the caeca $v s$ the intestine varied from fish to fish, the sexual difference in microhabitat use was rather consistent and appears characteristic for E. borealis (Fig. 2B). We discuss three factors possibly contributing to the sexual 
differences in gut distribution: (1) nutrients, (2) worm mortality and (3) mating opportunities.

First, helminth gut position is often assumed to reflect nutrient gradients (e.g. Crompton 1973, Mettrick and Podesta 1974, Haukisalmi et al. 1998). Female E. borealis are larger than males, as is frequently the case in acanthocephalans (Poulin and Morand 2000). The caeca are a major site for the initial uptake of nutrients in gadoid fish like burbot (Buddington and Diamond 1986, Izvekova et al. 2013), so perhaps females preferentially occupy the caeca for access to higher quality food, which in turn facilitates growth to a larger and more fecund body size (Baldanova 2000). Females in the caeca, however, were not larger than those in the intestine. Also, in high intensity infections, worms did not shift their distribution or have reduced sizes, which suggests they are not nutrient limited.

Second, there may be an association between microhabitat and parasite survival. The adult sex ratio of $E$. borealis was female-biased. This pattern is common in acanthocephalans and is usually driven by higher male mortality (e.g. Tedla and Fernando 1970, Valtonen 1980, Brattey 1988, Lasee 1989). The biased sex ratio could also reflect elevated female transmission to fish, relative to males, but this seems less likely given that the sex ratio in the amphipod intermediate host is about $1: 1$ (Benesh and Valtonen 2007). Assuming males have a higher mortality rate than females, their over-representation in the intestine may simply reflect senescing males being passed through the intestine and out of fish at a higher rate. However, males in the posterior parts of the intestine were not larger (= older?) than those more anteriorly located, which does not support this idea. Alternatively, the microhabitat distribution may cause sexual differences in longevity, rather than vice versa. For example, if peristalsis is weaker in the caeca than in the intestine (Crompton 1973), then the probability of females being dislodged may be lower, leading to the biased sex ratio.

Finally, sexual site segregation may reflect mating strategies. From the female perspective, a single mating may be sufficient to obtain all the sperm necessary to fertilise her eggs (Crompton 1974), so congregating with males is likely unneeded. But why do males not move into the caeca to have more contact with females? Burbot have tens of pyloric caeca (Hanson and Qadri 1980), so finding females in the caeca may require extensive searching compared to the intestine. Also, males are not more likely to find larger females in the caeca. Nonetheless, there was a tendency for relatively more males to be in the caeca when a larger fraction of the females in a fish were found there. This is consistent with males moving in response to mating opportunities, but this result must be interpreted very cautiously, as its significance was strongly dependent on a single infrapopulation.

One possible benefit for males in the anterior intestine is an increased probability to encounter newly recruited females. For example, in the acanthocephalan Leptorhynchoides thecatus Kostylew, 1924, females arrive in the anterior intestine before migrating into the caeca (Leadabrand and Nickol 1993, Richardson et al. 2008). Larvae of E. borealis are rather well developed (Benesh and Valtonen 2007), so mating probably occurs shortly after transmission to fish. We observed very few females without eggs, which supports this notion. Males would benefit from mating with virgin females arriving in the anterior intestine if sperm precedence, i.e. being the first to inseminate a female, is essential for fertilisation success. Sperm precedence is likely important in acanthocephalans, given that males leave copulatory plugs on females, presumably to prevent insemination by subsequent males (Parker 1984, Crompton 1985). However, we did not find small, presumably young females more commonly in the intestine.

In some acanthocephalan species, males congregate around unmated females (Awachie 1966, Serov 1985, Sinisalo et al. 2004), but in others they congregate with gravid females (Robinson and Barger 2007) or show no preference at all (Crompton and Whitfield 1968, Kennedy et al. 1976, Richardson and Barger 2005). Thus, acanthocephalan mating dynamics appears to vary between species. In the case of E. borealis, mating strategy is just one of several non-exclusive explanations for the dissimilar intestinal distributions of males and females. The relative importance of nutrition, mortality and reproduction on site selection remains to be determined.

Acknowledgements. We thank Sven Nikander for the life cycle drawing. DPB gratefully acknowledges support from the DFG (BE 5336/1-1).

\section{REFERENCES}

Agresti A. 2013: Categorical Data Analysis. John Wiley \& Sons, Hoboken, NJ, 744 pp.

Al-Jahdali M.O., El-Said Hassanine R.M. 2012: Infrapopulations of Sclerocollum saudii Al-Jahdali, 2010 (Acanthocephala: Cavisomidae) in the rabbitfish Siganus rivulatus (Teleostei, Siganidae) from the Saudi coast of the Red Sea. J. Helminthol. 86: 85-94.

AwACHIE J.B.E. 1966: The development and life-history of Echinorhynchus truttae Schrank 1788 (Acanthocephala). J. Helminthol. 40: 11-32.

Aznar F.J., Bush A.O., Balbuena J.A., Raga J.A. 2001: Corynosoma cetaceum in the stomach of franciscanas, Pontoporia blainvillei (Cetacea): an exceptional case of habitat selection by an acanthocephalan. J. Parasitol. 87: 536-541.
BALDANOVA D.R. 2000: [A fecundity of proboscis worms of the genus Echinorhynchus (Acanthocephala: Echinorhynchidae) from the Baikal Lake.] Parazitologiya 34: 150-153. (In Russian.)

Benesh D.P., Kitchen J., Pulkkinen K., Hakala I., ValtoNEN E.T. 2008: The effect of Echinorhynchus borealis (Acanthocephala) infection on the anti-predator behavior of a benthic amphipod. J. Parasitol. 94: 542-545.

Benesh D.P., Valtonen E.T. 2007: Sexual differences in larval life history traits of acanthocephalan cystacanths. Int. J. Parasitol. 37: 191-198.

Brattey J. 1988: Life history and population biology of adult Acanthocephalus lucii (Acanthocephala, Echinorhynchidae). J. Parasitol. 74: 72-80. 
Buddington R.K., Diamond J.M. 1986: Aristotle revisited: the function of pyloric caeca in fish. Proc. Natl. Acad. Sci. USA 83: 8012-8014.

Bush A.O., Holmes J.C. 1986: Intestinal helminths of lesser scaup ducks: an interactive community. Can. J. Zool. 64: 142-152.

Bush A.O., Lafferty K.D., Lotz J.M., Shostak A.W. 1997: Parasitology meets ecology on its own terms: Margolis et al revisited. J. Parasitol. 83: 575-583.

Crompton D.W.T. 1973: The sites occupied by some parasitic helminths in the alimentary tract of vertebrates. Biol. Rev. Camb. Philos. Soc. 48: 27-83.

Crompton D.W.T. 1974: Experiments on insemination in Moniliformis dubius (Acanthocephala). Parasitology 68: 229-238.

Crompton D.W.T. 1985: Reproduction. In: Crompton D.W.T. and Nickol B.B. (Eds.), Biology of the Acanthocephala. Cambridge University Press, Cambridge, pp. 213-272.

Crompton D.W.T., Whitfield P.J. 1968: The course of infection and egg production of Polymorphus minutus (Acanthocephala) in domestic ducks. Parasitology 58: 231-246.

Grabda-Kazubska B., Ejsymont L. 1969: Studies on the morphology, variability and systematic status of Echinorhynchus borealis Linstow, 1901 (Acanthocephala, Echinorhynchidae). Acta Parasitol. Pol. 17: 65-87.

HANSON J.M., QADRI S.U. 1980: Morphology and diet of young-ofthe-year burbot, Lota lota, in the Ottawa River. Can. Field Nat. 94: 311-314.

Haukisalmi V., Heino M., Kaitala V. 1998: Body size variation in tapeworms (Cestoda): adaptation to intestinal gradients? Oikos 83: 152-160.

Hill C. 1988: Life cycle and spatial distribution of the amphipod Pallasea quadrispinosa in a lake in northern Sweden. Holarct. Ecol. 11: 298-304.

Holmes J. 1961: Effects of concurrent infections on Hymenolepis diminuta (Cestoda) and Moniliformis dubius (Acanthocephala). I. General effects and comparison with crowding. J. Parasitol. 47: 209-216.

Izvekova G.I., Solovyev M.M., Kashinskaya E.N., Izvekov E.I. 2013: Variations in the activity of digestive enzymes along the intestine of the burbot Lota lota expressed by different methods. Fish Physiol. Biochem. 39: 1181-1193.

KenNedy C.R. 1985: Site segregation by species of Acanthocephala in fish, with special reference to eels, Anguilla anguilla. Parasitology 90: 375-390.

Kennedy C.R., Broughton P.F., Hine P.M. 1976: The sites occupied by the acanthocephalan Pomphorhynchus laevis in the alimentary canal of fish. Parasitology 72: 195-206.

KENNEDY C.R., LORD D. 1982: Habitat specificity of the acanthocephalan Acanthocephalus clavula (Dujardin, 1845) in eels Anguilla anguilla (L). J. Helminthol. 56: 121-130.

Kramer M., Schmidhammer J. 1992: The chi-squared statistic in ethology: use and misuse. Anim. Behav. 44: 833-841.

LASEE B. 1989: Seasonal population dynamics and maturation of Neoechinorhynchus pungitius (Acanthocephala: Neoechinorhynchidae) infecting brook stickleback, Culaea inconstans, from Sioux Creek, Wisconsin, U.S.A. Can. J. Zool. 67: 590-595.

Leadabrand C.C., Nickol B.B. 1993: Establishment, survival, site selection and development of Leptorhynchoides thecatus in largemouth bass, Micropterus salmoides. Parasitology 106: 495-501.

McPhail J.D., Paragamian V.L. 2000: Burbot biology and life history. In: V.L. Paragamian and D.W. Willis (Eds.), Burbot: Biology, Ecology, and Management. American Fisheries Society,
Fisheries Management Section, Publication 1, Spokane, Washington, pp. 11-23.

MetTrick D.F., Podesta R.B. 1974: Ecological and physiological aspects of helminth-host interactions in the mammalian gastrointestinal canal. Adv. Parasitol. 12: 183-278.

Mettrick D.F., Podesta R.B. 1982: Effect of gastrointestinal hormones and amines on intestinal motility and the migration of Hymenolepis diminuta in the rat small intestine. Int. J. Parasitol. 12: 151-154.

Moore J., Simberloff D. 1990: Gastrointestinal helminth communities of bobwhite quail. Ecology 71: 344-359.

Parker G.A. 1984: Sperm competition and the evolution of animal mating strategies. In: R.L. Smith (Ed.), Sperm Competition and the Evolution of Animal Mating Systems. Academic Press, Orlando, FL, pp. 1-60.

Poulin R., Morand S. 2000: Testes size, body size and male-male competition in acanthocephalan parasites. J. Zool. 250: 551-558.

Richardoson D.J., Barger M.A. 2005: Microhabitat specificity of Macracanthorhynchus ingens (Acanthocephala: Oligacanthorhynchidae) in the raccoon (Procyon lotor). Comp. Parasitol. 72: 173-178.

RichaRdSON D.J., NickOL B.B. 2000: Experimental investigation of physiological factors that may influence microhabitat specificity exhibited by Leptorhynchoides thecatus (Acanthocephala) in green sunfish (Lepomis cyanellus). J. Parasitol. 86: 685-690.

Richardson K.E., Richardson D.J., Nickol B.B. 2008: Emigration of Leptorhynchoides thecatus (Acanthocephala) in green sunfish (Lepomis cyanellus). Comp. Parasitol. 75: 49-51.

Robinson H.A., BARGer M.A. 2007: Microhabitat specificity of Paulisentis missouriensis (Acanthocephala) in creek chub (Semotilus atromaculatus) in southeastern Nebraska, USA. Comp. Parasitol. 74: 355-358.

RoHDE K. 1994: Niche restriction in parasites: proximate and ultimate causes. Parasitology 109: S69-S84.

SegerstrÅle S.G. 1962: The immigration and prehistory of the glacial relicts of Eurasia and North America. A survey and discussion of modern views. Int. Rev. Gesamten Hydrobiol. Hydrogr. 47: 1-25.

Serov V.G. 1985: [The distribution of Acanthocephalus lucii (Müller) (Palaeacanthocephala, Echinorhynchidae) in the gut of perch.] Parazitologiya 19: 85-87. (In Russian.)

Sinisalo T., Poulin R., Hogmander H., Juuti T., Valtonen E.T. 2004: The impact of sexual selection on Corynosoma magdaleni (Acanthocephala) infrapopulations in Saimaa ringed seals (Phoca hispida saimensis). Parasitology 128: 179-185.

Tedla S., Fernando C. 1970: Some remarks on the ecology of Echinorhynchus salmonis Müller 1784. Can. J. Zool. 48: 317-321.

Uglem G.L., Beck S.M. 1972: Habitat specificity and correlated aminopeptidase activity in the acanthocephalans Neoechinorhynchus cristatus and $N$. crassus. J. Parasitol. 58: 911-920.

VALtonen E.T. 1980: Metechinorhynchus salmonis (Müller, 1780) (Acanthocephala) as a parasite of the whitefish in the Bothnian Bay. II. Sex ratio, body length and embryo development in relation to season and site in intestine. Acta Parasitol. Pol. 27: 301-307.

Valtonen E.T., Crompton D.W.T. 1990: Acanthocephala in fish from the Bothnian Bay, Finland. J. Zool. 220: 619-639.

Wayland M.T., Vainio J.K., Gibson D.I., Herniou E.A., LitTLEWOOD D.T.J., VÄINÖLÄ R. 2015: The systematics of Echinorhynchus Zoega in Müller, 1776 (Acanthocephala, Echinorhynchidae) elucidated by nuclear and mitochondrial sequence data from eight European taxa. Zookeys 484: 25-52. 